\title{
Chemical Composition and Insecticidal Activity of Essential Oil of Artemisia frigida Willd (Compositae) against Two Grain Storage Insects
}

\author{
Xin Chao Liu ${ }^{1}$, Yonglan $\mathrm{Li}^{2}$, Tiejuan Wang ${ }^{2}$, Qing Wang ${ }^{2}$ and Zhi Long Liu ${ }^{1 *}$ \\ ${ }_{1}^{1}$ Department of Entomology, China Agricultural University, 2 Yuanmingyuan West Road, Haidian District, Beijing 100193, \\ ${ }^{2}$ College of Life Sciences and Technology, Inner Mongolia Normal University, Hohhot, Inner Mongolia 010022, China
}

*For correspondence: Email: zhilongliu@cau.edu.cn; Tel: +86-10-62732800; Fax: +86-10-62732800

\begin{abstract}
Purpose: To investigate the chemical composition and insecticidal activity of the essential oil of the aerial parts of Artemisia frigida against maize weevils (Sitophilus zeamais) and booklice (Liposcelis bostrychophila).

Methods: Steam distillation of A. frigida aerial parts was carried out in a Clavenger apparatus to extract its volatile oil content. Gas chromatography/mass spectrometric (GC/MS) analyses (HP-5MS column) of the essential oil were performed and its contact toxicity was determined using topical application and filter paper impregnation technique while its fumigant toxicity was evaluated using sealed-space method.

Results: A total of 32 components of the essential oil were identified. The principal compounds were cis- $\rho$-menth-2-en-1-ol (20.8\%), 1,8-cineole (12.0\%), borneol (10.2\%), lavandulol (9.3\%), camphor (6.9\%), and bicyclogermacrene (5.5\%). The oil exhibited contact toxicity against adult S. zeamais and $L$. bostrychophila with $L C_{50}$ value of $17.97 \mu \mathrm{g} / \mathrm{adult}$ and $254.38 \mu \mathrm{g} / \mathrm{cm}^{2}$, respectively. The essential oils also possessed fumigant toxicity against $S$. zeamais and $L$. bostrychophila with $L C_{50}$ value of 69.46 $\mathrm{mg} / \mathrm{L}$ and $1.25 \mathrm{mg} / \mathrm{L}$ air.

Conclusion: The study indicates that the essential oil of A. frigida has a potential to be developed to a natural fumigant/insecticide for the control of grain storage insects.
\end{abstract}

Keywords: Artemisia frigida, Sitophilus zeamais, Liposcelis bostrychophila, Insecticidal activity, Essential oil, Cis- $\rho$-Menth-2-en-1-ol; 1,8-Cineole

Tropical Journal of Pharmaceutical Research is indexed by Science Citation Index (SciSearch), Scopus, International Pharmaceutical Abstract, Chemical Abstracts, Embase, Index Copernicus, EBSCO, African Index Medicus, JournalSeek, Journal Citation Reports/Science Edition, Directory of Open Access Journals (DOAJ), African Journal Online, Bioline International, Open-J-Gate and Pharmacy Abstracts

\section{INTRODUCTION}

The genus Artemisia belongs to the family Asteraceae (Compositae) and is a large, diverse genus of plants with about 380 species in the world, of which 186 species (82 endemic) are distributed in China [1]. Many species are rich in iso/chlorogenic acid, polyacetylenes, flavonoids, terpenoids, sesquiterpene lactones, and cyanogenic glycosides and are well-known medicinal plants [2]. Fringed sagebrush
(Artemisia frigida Willd.) is a perennial semishrub distributed in the heavily grazed grasslands in Inner Mongolia, Qinghai, and Gansu Provinces in China [1]. The aerial part of $A$. frigida is a commonly used medical material in Mongolian folk medicine to treat joint swelling, renal heat, abnormal menstruation, and sore carbuncle, and is also one of the components of 'artificial holy water' [3]. Sesquiterpenoids, sesquiterpene lactone glycosides, coumarins and flavonoids have been reported from A. frigida [4- 
6]. The chemical composition of the essential oils derived from $A$. frigida aerial parts has also been determined [7-9].

During the screening program for new agrochemicals from Chinese medicinal herbs and wild plants, the essential oil of $A$. frigida aerial parts was found to possess insecticidal toxicity against maize weevils (Sitophilus zeamais Motsch.) and booklice (Liposcelis bostrychophila Badonnel) [10]. Essential oils of several Chinese Artemisia species were demonstrated to possess insecticidal activity to grain storage insects [11-13]. However, a literature survey shows that there is no report on insecticidal activity of the essential oil derived from A. frigida aerial parts. Thus, the objective of this study was to investigate the chemical constituents and insecticidal activity of the essential oil of $A$. frigida aerial parts against the two grain storage insects.

\section{EXPERIMENTAL}

\section{Plant collection and identification}

The aerial parts of $A$. frigida were collected in August 2012 from suburbs of Hohhot $\left(40.48^{\circ} \mathrm{N}\right.$ latitude and $111.41^{\circ} \mathrm{E}$ longitude, Inner Mongolia 010022). The samples were air-dried and identified by Dr. Liu, (College of Life Sciences, Beijing Normal University, Beijing 100875, China) and a voucher specimen (no. ENTCAUCompositae-10017) was deposited at the Department of Entomology, China Agricultural University (Beijing 100193).

\section{Extraction and isolation of essential oil}

The samples were ground to powder using a grinding mill (Retsch Muhle, Germany). The powder $(5 \mathrm{~kg})$ was hydro-distilled for $6 \mathrm{~h}$ in a Clavenger apparatus. The oil was dried over anhydrous $\mathrm{Na}_{2} \mathrm{SO}_{4}$ and kept in a refrigerator $\left(4^{\circ} \mathrm{C}\right)$ pending subsequent experiments.

\section{Analysis of essential oil}

Capillary gas chromatography was performed using Hewlett-Packard 5890 gas chromatograph equipped with a flame ionization detector and fused silica capillary column HP-5 (5\% diphenyl and $95 \%$ dimethylpolysyloxane, $30 \mathrm{~m} \times 0.25 \mathrm{~mm}$, $0.25 \mu \mathrm{m}$ film thickness), at a flow rate of $1 \mathrm{~mL}$ $\mathrm{min}^{-1}$. Temperature was programmed from 60 to $280^{\circ} \mathrm{C}$ (at a rate of $2^{\circ} \mathrm{C} \mathrm{min}^{-1}$ ); injector and detector temperatures were $270^{\circ} \mathrm{C}$ and $300^{\circ} \mathrm{C}$, respectively. The components of the essential oils were separated and identified by gas chromatography-mass spectrometry (GC-MS) using Agilent $6890 \mathrm{~N}$ gas chromatography coupled to Agilent 5973N mass selective detector. The system was equipped with a flame ionization detector and capillary column with HP$5 \mathrm{MS}(30 \mathrm{~m} \times 0.25 \mathrm{~mm} \times 0.25 \mu \mathrm{m})$. GC settings were as follows: the initial oven temperature was held at $60^{\circ} \mathrm{C}$ for $1 \mathrm{~min}$ and ramped at $10^{\circ} \mathrm{C} \mathrm{min}{ }^{-1}$ to $180^{\circ} \mathrm{C}$ where it was held for $1 \mathrm{~min}$, and then ramped at $20^{\circ} \mathrm{C} \mathrm{min}^{-1}$ to $280^{\circ} \mathrm{C}$ and held there for $15 \mathrm{~min}$. The injector temperature was maintained at $270^{\circ} \mathrm{C}$. The samples $(1 \mu \mathrm{L}$, diluted to $100: 1$ with acetone) were injected, with a split ratio of 1:10. The carrier gas was helium at a flow rate of $1.0 \mathrm{ml} \mathrm{min}^{-1}$. Spectra were obtained over the scan range 20 to $550 \mathrm{~m} / \mathrm{z}$ at 2 scans $\mathrm{s}^{-1}$. Most constituents were identified by gas chromatography by comparison of their retention indices with those published in the literature or with those of authentic compounds available in our laboratories. Retention index was determined in relation to a homologous series of $n$-alkanes (C8-C24) under the same operating conditions. Further identification was made by comparison of their mass spectra with those stored in NIST 05 and Wiley 275 libraries or with mass spectra from literature [14]. Relative proportions (\%) of the oil components were calculated based on GC peak areas without using correction factors.

\section{Rearing of insects}

S. zeamais was obtained from laboratory cultures maintained for the last 10 years in the dark in incubators at $27-29^{\circ} \mathrm{C}$ and $70-80 \%$ relative humidity. Adult $S$. zeamais insects were reared on whole wheat at $12-13 \%$ moisture content in glass jars (diameter $85 \mathrm{~mm}$, height $130 \mathrm{~mm}$ ). Unsexed adults of the insects used in all the experiments were about one week old. All containers housing insects and the petri dishes used in experiments were made escape-proof with a coating of polytetrafluoroethylene (Fluon, Blades Biological, UK).

Booklice (L. bostrychophila) were obtained from laboratory cultures in the dark in incubators at $28-30^{\circ} \mathrm{C}$ and $70-80 \%$ r.h. and reared on a $1: 1: 1$ mixture, by mass, of milk powder, active yeast, and flour. All the containers housing insects and the Petri dishes used in experiments were made escape proof with a coating of polytetrafluoroethylene (Fluon $\AA$, Blades Biological, UK). Laboratory bioassays were done within one week after adult collections.

\section{Fumigant toxicity test}

The fumigant toxicity of the essential oil against S. zeamais was determined as described [15]. A Whatman filter paper (diameter $2.0 \mathrm{~cm}$, CAT no. 
1001020) was placed on the underside of the screw cap of a glass vial (diameter $2.5 \mathrm{~cm}$, height $5.5 \mathrm{~cm}$, volume $24 \mathrm{~mL}$ ). Range-finding studies were run to determine the appropriate testing concentrations $(2.0-40.0 \%$, six concentrations). Ten microliters of essential oil solution was added to the filter paper. The solvent was allowed to evaporate for $15 \mathrm{~s}$ before the cap was placed tightly on the glass vial (containing 10 unsexed insects) to form a sealed chamber. Fluon ( $\mathrm{ICl}$ America Inc) was used inside the glass vial to prevent insects from the treated filter paper. n-Hexane was used as controls and six replicates were used in all treatments and controls. They were incubated at $27-29^{\circ} \mathrm{C}$ and $70-80 \%$ relative humidity for 24 $\mathrm{h}$ and mortality of insects was observed.

The fumigant toxicity of the essential oil against L. bostrychophila was determined as described [16]. A filter paper strip $(3.5 \mathrm{~cm} \times 1.5 \mathrm{~cm})$ treated with $10 \mu \mathrm{L}$ of an appropriate concentration $(0.80$, $1.0,1.8,2.7,4.0$, and $6.0 \%$ ) of the essential oil in acetone. The impregnated filter paper was then placed in the bottom cover of glass bottle of 250 $\mathrm{ml}$. The insects, 10 adults in a small glass bottle $(8 \mathrm{ml})$, were exposed for $24 \mathrm{~h}$ and all the treatments were replicated five times. Acetone was used as negative control and dichlorvos as positive control (purchased from Aladdin-reagent Company (Shanghai, China).

\section{Contact toxicity test using topical application}

The contact toxicity of the essential oil against $S$. zeamais was determined as described previously [15]. A serial dilution of the essential oil (6 concentrations, 2.6-13.3\% v/w) was prepared in $\mathrm{n}$-hexane. Aliquots of $0.5 \mu \mathrm{l}$ of the dilutions were applied topically to the dorsal thorax of the insects. Controls were determined using nhexane. Six replicates were used in all treatments and controls. Both treated and control insects were then transferred to glass vials (10 insects/vial) with culture media and kept in incubators. Mortality of insects was observed after $24 \mathrm{~h}$. Pyrethrum extract (containing 25\% pyrethrin I and pyrethrin II) was purchased from Fluka Chemie.

\section{Contact toxicity test with treated filter paper}

The contact toxicity of the essential oil against $L$. bostrychophila was determined as previously described [16]. The essential oil was diluted in acetone. The filter paper with $3.5 \mathrm{~cm}$ in diameter (Whatman) was treated with $150 \mu \mathrm{L}$ of the solution. Then the filter paper after treated with solid glue (Glue Stick, Jong le Nara Co., Ltd. Hong Kong) was placed in a Petri dish $(3.5 \mathrm{~cm}$ in diameter) and 10 booklice were put on the filter paper by using a hair brush. The plastic cover with holes was put and all the Petri dishes were kept in incubators at $27-29^{\circ} \mathrm{C}, 70-80 \%$ r.h. for 24 h. Acetone was used as controls and pyrethrum extract was used as a positive control. Six concentrations $(1.0,1.2,1.5,1.8,2.2$, and $4.5 \%)$ and five replicates of each concentration were used in all treatments and controls.

\section{Statistical analysis}

The results from all replicates in fumigant and contact toxicity were subjected to Probit analysis [17] using PriProbit Program V1.6.3 to determine $\mathrm{LD}_{50}$ and $\mathrm{LC}_{50}$ values, respectively [18]. Samples for which the $95 \%$ fiducial limits did not overlap were considered to be significantly different.

\section{RESULTS}

The essential oil was yellow with a yield of $0.19 \%$ $\mathrm{v} / \mathrm{w}$ and density of $0.89 \mathrm{~g} / \mathrm{ml}$. A total of 32 components of the essential oil were identified, accounting for $96.54 \%$ of the total oil. The major compounds in the essential oil were cis- $\rho$-menth2-en-1-ol (20.80\%), 1,8-cineole (11.98\%), borneol (10.22\%), lavandulol $(9.29 \%)$, camphor $(6.89 \%)$, and bicyclogermacrene $(5.53 \%)$ (Table 1). Monoterpenoids represented 21 of the 32 compounds, corresponding to $78.42 \%$ of the whole oil while 10 of the 32 constituents were sesquiterpenoids ( $17.62 \%$ of the oil).

\section{DISCUSSION}

The main constituents of the essential oil of $A$. frigida aerial parts were cis- $\rho-m e n t h-2-e n-1-o l$, 1,8-cineole, borneol, lavandulol, camphor, and bicyclogermacrene. Its chemical composition is slightly different from that collected from different populations. For example, major compounds in the sample collected from Xinjiang province, China were 1,8-cineole (18.05\%), camphor (16.01\%), borneol (4.98\%), and trans-2-pinen-4ol $(4.85 \%)$ [20]. However, the essential oil of $A$. frigida aerial parts harvested from Siberian region mainly contains camphor $(49.89 \%)$, 1,8cineol $(8.99 \%)$, and borneol $(8.32 \%)$ [9] while 1,8-cineole $(24.7 \%)$, camphor $(22.6 \%)$, borneol $(8.9 \%), \beta$-thujone $(5.2 \%)$ and camphene $(4.2 \%)$ were major constituents in the essential of $A$. frigida from Kazakhstan region [21]. The essential oil of $A$. frigida aerial parts harvested from Western Canada have 1,8-cineole (25.1\%), camphor $(20.6 \%)$, chrysanthemone $(7.4 \%)$, and camphene $(4.1 \%)$ [22]. The differences in oil composition was slight as 2 to 3 components 
Table 1: Composition of essential oil of Artemisia frigida aerial parts

\begin{tabular}{|c|c|c|c|}
\hline Peak no. & Compound & Retention index & (\%) composition \\
\hline 1 & a-Pinene & 939 & 0.12 \\
\hline 2 & $\beta$-Pinene & 974 & 0.11 \\
\hline 3 & 2,3-Dehydro-1,8-cineole & 989 & 0.28 \\
\hline 4 & $\delta$-3-Carene & 1016 & 0.85 \\
\hline 5 & 1,8-Cineole & 1032 & 11.98 \\
\hline 6 & ү-Terpinene & 1060 & 0.08 \\
\hline 7 & cis-Linalool oxide & 1067 & 0.56 \\
\hline 8 & Artemisia alcohol & 1083 & 0.38 \\
\hline 9 & Terpinolene & 1088 & 3.87 \\
\hline 10 & Linalool & 1094 & 2.59 \\
\hline 11 & $\alpha$-Thujone & 1105 & 0.32 \\
\hline 12 & $\beta$-Thujone & 1114 & 0.90 \\
\hline 13 & cis-p-Menth-2-en-1-ol & 1117 & 20.80 \\
\hline 14 & trans-p-Menth-2-en-1-ol & 1142 & 1.30 \\
\hline 15 & Camphor & 1146 & 6.89 \\
\hline 16 & Borneol & 1160 & 10.22 \\
\hline 17 & Lavandulol & 1170 & 9.29 \\
\hline 18 & 4-Terpineol & 1175 & 3.77 \\
\hline 19 & $\alpha$-Terpineol & 1189 & 3.21 \\
\hline 20 & Grandisol & 1200 & 0.70 \\
\hline 21 & Bornyl acetate & 1287 & 0.20 \\
\hline 22 & Eugenol & 1356 & 0.50 \\
\hline 23 & Caryophyllene & 1420 & 1.17 \\
\hline 24 & Germacrene D & 1485 & 1.42 \\
\hline 25 & $\beta$-Selinene & 1490 & 0.60 \\
\hline 26 & $\beta$-Guaiene & 1491 & 2.63 \\
\hline 27 & Virdiflorene & 1495 & 1.22 \\
\hline 28 & Bicyclogermacrene & 1513 & 5.53 \\
\hline 29 & Spathulenol & 1572 & 1.56 \\
\hline 30 & Caryophyllene oxide & 1583 & 0.43 \\
\hline 31 & Cedrol & 1608 & 1.79 \\
\hline \multirow[t]{5}{*}{32} & $\beta$-Eudesmol & 1649 & 1.27 \\
\hline & Total & & 96.54 \\
\hline & Monoterpenoids & & 78.42 \\
\hline & Sesquiterpenoids & & 17.62 \\
\hline & Others & & 0.50 \\
\hline
\end{tabular}

${ }^{*} R I$ (retention index), as determined on a HP-5MS column using the homologous series of $n$-hydrocarbons

Table 2: Toxicity of Artemisia frigida essential oil against adult Sitophilus zeamais

\begin{tabular}{|c|c|c|c|c|c|c|}
\hline \multirow[t]{2}{*}{ Treatment } & \multicolumn{3}{|c|}{ Contact toxicity } & \multicolumn{3}{|c|}{ Fumigant toxicity } \\
\hline & $\begin{array}{c}L C_{50} \\
(\mu g / a d u l t) \\
(95 \% \text { FL) }\end{array}$ & $\begin{array}{l}\text { Slope } \pm \\
\text { SE }\end{array}$ & $\begin{array}{c}\text { Chi } \\
\text { square } \\
\left(x^{2}\right)\end{array}$ & $\begin{array}{c}L C_{50}(\mathrm{mg} / \mathrm{L} \text { air }) \\
(95 \% \mathrm{FL})\end{array}$ & Slope $\pm S E$ & $\begin{array}{c}\text { Chi } \\
\text { square } \\
\left(x^{2}\right)\end{array}$ \\
\hline $\begin{array}{l}\text { A. frigida } \\
\text { Mean Range }\end{array}$ & $\begin{array}{c}50.18 \\
(44.42-56.49)\end{array}$ & $3.27 \pm 0.33$ & 22.68 & $\begin{array}{c}69.46 \\
(60.43-79.27)\end{array}$ & $2.70 \pm 0.29$ & 12.60 \\
\hline $\begin{array}{l}\text { Pyrethrum extract } \\
\text { Mean Range }\end{array}$ & $\begin{array}{c}4.29^{*} \\
(3.86-4.72)\end{array}$ & $0.72 \pm 0.01$ & 13.51 & - & - & - \\
\hline $\mathrm{MeBr}^{* * *}$ & - & - & - & $0.67^{* *}$ & - & - \\
\hline
\end{tabular}

occurred in oil from other locations. The above findings suggest that 1,8-cineole, camphor and borneol are three major constituents in the essential oils of $A$. frigida from different populations.

The essential oil of $A$. frigida exhibited contact toxicity against $S$. zeamais and $L$. bostrychophila. However, compared with the positive control
(Pyrethrum extract, LD ${ }_{50}$ values of $4.3 \mu \mathrm{g} /$ insect [19] and $19.0 \mu \mathrm{g} / \mathrm{cm}^{2}$, respectively), acute toxicity against the weevil and booklice was weak. The essential oil also showed fumigant toxicity against adult S. zeamais and L. bostrychophila. The commercial grain fumigant, methyl bromide (MeBr), is reported to possess fumigant activity against $S$. zeamais adults with an $L_{50}$ value of0.67 mg/L [23]. 
Table 3: Toxicity of Artemisia frigida essential oil against Liposcelis bostrychophila

\begin{tabular}{|c|c|c|c|c|c|c|}
\hline \multirow[t]{2}{*}{ Treatment } & \multicolumn{3}{|c|}{ Contact toxicity } & \multicolumn{3}{|c|}{ Fumigant toxicity } \\
\hline & $\begin{array}{c}L C_{50}\left(\mu \mathrm{g} / \mathrm{cm}^{2}\right) \\
(95 \% \mathrm{FL})\end{array}$ & Slope $\pm S E$ & $\begin{array}{c}\text { Chi } \\
\text { square } \\
\left(x^{2}\right)\end{array}$ & $\begin{array}{c}L C_{50}(\mathrm{mg} / \mathrm{L} \text { air) } \\
(95 \% \mathrm{FL})\end{array}$ & Slope \pm SE & $\begin{array}{c}\text { Chi } \\
\text { square } \\
\left(x^{2}\right)\end{array}$ \\
\hline $\begin{array}{l}\text { A. frigida } \\
\text { Mean range }\end{array}$ & $\begin{array}{c}254.38 \\
(209.51-327.01)\end{array}$ & $6.78 \pm 0.69$ & 18.76 & $\begin{array}{c}1.25 \\
(1.09-1.41)\end{array}$ & $3.73 \pm 0.38$ & 19.88 \\
\hline $\begin{array}{l}\text { Dichlorvos } \\
\text { Mean range }\end{array}$ & - & - & - & $\begin{array}{c}1.35 \times 10^{-3} \\
(1.25-1.47) \times 10^{-3}\end{array}$ & - & - \\
\hline $\begin{array}{l}\text { Pyrethrum extract } \\
\text { Mean range }\end{array}$ & $\begin{array}{c}18.99 \\
17.56-20.06 \\
\end{array}$ & - & - & - & - & - \\
\hline
\end{tabular}

Thus, the essential oil is 100 times less toxic to adult $S$. zeamais than with $\mathrm{MeBr}$.

However, compared with the fumigant activity of the other essential oils reported in the literature and which were tested using a similar bioassay, the essential oil obtained in the present study exhibited the same or stronger fumigant toxicity against maize weevils, e.g., the essential oils of A. vestita [11], $A$. eriopoda [13], $A$. lavandulaefolia and $A$. sieversiana [15], $A$. capillaris and $A$. mongolica [23], $A$. giraldii and $A$. subdigitata [12], and $A$. igniaria [24]. The essential oil of $A$. frigida aerial parts also possessed the same level of fumigant toxicity to the booklice as that of essential oils of Foeniculum vulgare [16], Illicium pachyphyllum fruits [25], and Curcuma wenyujin rhizomes [26].

The foregoing suggest that the fumigant activity of the essential oil of $A$. frigida has some promise as a possible natural fumigant/insecticide for the control of grain storage insects, especially as currently used fumigants are synthetic insecticides and the most effective fumigants are also highly toxic to humans and other non-target organisms [27]. However, to develop a practical application for the essential oil as novel fumigant/insecticide, further research into the safety of the essential oil in humans is needed. Additional studies on the development of formulations are also necessary to improve efficacy and stability as well as to reduce cost.

\section{CONCLUSION}

The essential oil of $A$. frigida aerial parts demonstrated some activity against maize weevil but needs to be further evaluated for safety in humans and to enhance its activity. The principal compounds found in the essential oil of $A$. frigida aerial parts harvested from Inner Mongolia were cis-p-menth-2-en-1-ol, 1,8-cineole, and borneol.

\section{ACKNOWLEDGEMENT}

This work was funded by the Hi-Tech Research and Development of China 2011AA10A202. The authors thank Dr. QR Liu of the College of Life Sciences, Beijing Normal University, Beijing 100875 , for the identification of the investigated plant.

\section{REFERENCES}

1. Zhang DX, Hartley TG, Mabberley DJ. Flora of China. 2003. http://www.efloras.org/florataxon.aspx?flora_id $=2 \&$ taxon_id=102682.

2. Wang $Q H$, Sha $Y$, Ao WLJ, Wang $X L$, Bao XH, Li W, Wang $\mathrm{JH}$. Two new sesquiterpene lactone glycosides from Artemisia frigida Willd. J Asian Nat Prod Res 2011; 13: 645-651.

3. Bai QY. Chinese Medical Encyclopaedia- Mongolian Medicine. Inner Mongolia Science and Technology Press, Chifeng, China, 1986; p. 322.

4. Liu YL. Mabry TJ. Two methylated flavones from Artemisia frigida. Phytochemistry 1981; 20: 309-311.

5. Liu YL. Mabry TJ. Flavonoids from Artemisia frigida. Phytochemistry 1981; 20: 1389-1395.

6. Wang QH, Ao WLJ, Wang XL, Bao XH, Wang JH. Two new flavonoid glycosides from Artemisia frigida Willd. J Asian Nat Prod Res 2010; 12: 950-954.

7. Korolyuk EA, Tkachev AV. Chemical composition of the essential oil from two wormwood species Artemisia frigida and Artemisia argyrophylla. Russian J Bioorg Chem 2010; 36: 884-893.

8. Zuo ZJ, Zhang RM, Wang Y, Hou P, Wen GS, Gao Y. Analysis of main volatile organic compounds and study of aboveground structures in Artemisia frigida. Chin J Plant Ecol 2010; 34: 462-468.

9. Pushkareva ES, Efremov AA. Component composition of the essential oil of Artemisia frigida from Krasnoyarsk region and of its individual fractions. J Sorption Chromatogr Process 2012; 12: 619-623.

10. Liu ZL, Goh SH, Ho SH. Screening of Chinese medicinal herbs for bioactivity against Sitophilus zeamais Mostchulsky and Tribolium castaneum (Herbst). J Stored Prod Res 2007; 43: 290-296 
11. Chu SS, Liu QR, Liu ZL. Insecticidal activity and chemical composition of the essential oil of Artemisia vestita from China. Biochem Syst Ecol 2010; 38: 489-492.

12. Chu SS, Liu ZL, Du SS, Deng ZW. Chemical composition and insecticidal activity of the essential oils derived from Artemisia giraldii and Artemisia subdigitata against Sitophilus zeamais. Molecules 2012; 17: 7255-7265.

13. Jiang GH, Liu QR, Chu SS, Liu ZL. Chemical composition and insecticidal activity of the essential oil of Artemisia eriopoda against maize weevil, Sitophilus zeamais. Nat Prod Communications 2012; 7: 267268.

14. Adams RP. Identification of Essential Oil Components by Gas Chromatograph /Mass Spectrometry. 4th ed. Allured Publishing Corpoartion, Carol Stream, USA, 2007.

15. Liu ZL, Liu QR, Chu SS, Jiang GH. Insecticidal activity and chemical composition of the essential oils of Artemisia lavandulaefolia and Artemisia sieversiana from China. Chem Biodivers 2010; 7: 2040-2045.

16. Zhao NN, Zhou L, Liu ZL, Du SS, Deng ZW. Evaluation of toxicities of some common spices essential oils from China against Liposcelis bostrychophila. Food Control 2012; 26: 486-490.

17. Finney DJ. Probit analysis. 3rd ed. Cambridge University, London. 1971.

18. Sakuma M. Probit analysis of preference data. Appl Entomol Zool 1998; 33: 339-347.

19. Liu ZL, Ho SH. Bioactivity of the essential oil extracted from Evodia rutaecarpa Hook $f$. et Thomas against the grain storage insects, Sitophilus zeamais Motsch. and Tribolium castaneum (Herbst). J Stored Prod Res 1999; 35: 317-328.
20. He $X Q, X u G Q$, Yu F, Wang $H$, Zhang $Y L, L i R$. The volatile constitutes of Seriphidium santolium and Artemisia frigida by GC/MS. J Chin Mass Spectrometry Soc 2009; 30: 314-320.

21. Atazhanova GA, Dembitskii AD, Yakovleva TD, Ishmuratova MY, Mikhailov VG, Adekenov SM. Composition of the essential oils of Artemisia radicans and A. frigida. Chem Nat Compds 2000; 35, 427-429.

22. Lopes-Lutz D, Alviano DS, Alviano CS, Kolodziejczyk PP. Screening of chemical composition, antimicrobial and antioxidant activities of Artemisia essential oils. Phytochemistry 2008; 69: 1732-1738.

23. Liu ZL, Chu SS, Liu QR Chemical composition and insecticidal activity against Sitophilus zeamais of the essential oils of Artemisia capillaris and Artemisia mongolica. Molecules 2010; 15: 2600-2608.

24. Chu SS, Du SS, Liu QZ, Liu QR, Liu ZL. Composition and insecticidal activity of the essential oil of Artemisia igniaria flowering aerial parts against Sitophilus zeamais. J Med Plant Res 2012; 6: 3188-3192.

25. Liu P, Liu XC, Dong HW, Liu ZL, Du SS, Deng ZW. Chemical composition and insecticidal activity of the essential oil of Illicium pachyphyllum fruits against two grain storage insects. Molecules 2012; 17: 14870-14881.

26. Liu ZL, Zhao NN, Liu CM, Zhou L, Jiang GH. Identification of insecticidal constituents of the essential oil of Curcuma wenyujin rhizomes against Liposcelis bostrychophila Badonnel. Molecules 2012; 17: 12049-12060.

27. Zettler JL, Arthur FH. Chemical control of stored product insects with fumigants and residual treatments. Crop Prot 2000; 19: 577-582. 